\title{
Limiting transmission of COVID-19 in an inpatient psychiatric hospital using a special care unit as a behavioral health model - Michigan, March 1-August 31, 2020
}

\author{
William Sanders ${ }^{* 1,2,3}$, Kimberley Greenwald ${ }^{1,2,4}$, Joshua Foster ${ }^{1}$, David Meisinger ${ }^{1,3}$, Richelle Payea ${ }^{1,3}$, Harmony \\ Gould $^{1,2}$, Jessica Kross ${ }^{1,2}$, Carol A. Janney ${ }^{1,3,5}$ \\ ${ }^{1}$ Pine Rest Christian Mental Health Services, Grand Rapids, MI, United States \\ ${ }^{2}$ Pine Rest Covid-19 Response Team, Grand Rapids, MI, United States \\ ${ }^{3}$ Division of Psychiatry and Behavioral Medicine, Michigan State University College of Human Medicine, Grand Rapids, MI, \\ United States \\ ${ }^{4}$ Loyola University, Chicago, IL, United States \\ ${ }^{5}$ Department of Epidemiology and Biostatistics, Michigan State University College of Human Medicine, Grand Rapids, MI, \\ United States
}

Received: February 12, 2021

DOI: $10.5430 /$ jha.v10n3p25
Accepted: April 25, 2021

Online Published: May 14, 2021

URL: https://doi.org/10.5430/jha.v10n3p25

\begin{abstract}
Approximately 53,000 patients/year are admitted to psychiatric hospitals in Michigan and treatment typically involves social gatherings and group therapies (SAMHSA 2017; Michigan DHS 2019). Often psychiatric inpatients are in close proximity placing them at high risk of infection and have comorbid medical conditions that predispose them to severe COVID-19 consequences. In March 2020, Pine Rest Christian Mental Health Services, Grand Rapids, MI initiated protocols and precautions to mitigate the spread of COVID-19 between patients and health care personnel (HCP) based on emerging CDC guidelines. Multiple strategies [COVID-19 testing, masking of patients and HCP, restricting visitors, and creation of Special Care Unit (SCU) with negative pressure] were effectively implemented and limited transmission of COVID-19 within Pine Rest. Admission to the SCU totaled 25 adults (three Pine Rest patients who tested positive during or after admission, and 22 COVID-19 positive patients who were transferred from other facilities). Average age of SCU inpatients was $38.5 \pm 16.6$ years with the majority being male. Average hospitalization was $9 \pm 4$ days. Among the 21 COVID-19 positive HCP, 15 [71\%] provided direct clinical care on various units, zero provided care on the SCU, and six had roles with no direct patient care. Average age among COVID-19 positive HCP providing direct patient care[ $\mathrm{n}=15]$ was $29.5 \pm 13.5$ years, majority were female, and 3 [20\%] were admitted to local medical hospital for treatment. This report demonstrates that quality behavioral health care can be safely provided at inpatient psychiatric facilities and serve as a guideline that other psychiatric facilities can follow to decrease transmission in future epidemics.
\end{abstract}

Key Words: COVID-19, Psychiatric inpatient, SARS-CoV-2, Mental health

*Correspondence: William Sanders; Email: Bill.Sanders@PineRest.org; Address: 300 68th Street SE, Grand Rapids, MI, 49548, United States. 


\section{INTRODUCTION}

Approximately 53,000 patients are admitted annually to psychiatric hospitals in Michigan ${ }^{[1,2]}$ and treatment typically involves social gatherings (defined as three or more patients within six feet of each other for five minutes or longer) and group therapies. Often these psychiatric inpatients are in close proximity placing them at high risk of infection and have comorbid medical conditions that predispose them to severe COVID-19 consequences. Overall, 107,953 individuals in Michigan were diagnosed with COVID-19 between March 1 and August 31, 2020. ${ }^{[3]}$

Early in the pandemic, Pine Rest Christian Mental Health Services (Pine Rest) implemented robust infection prevention methods to mitigate the spread of COVID-19 between patients and health care personnel (HCP) based on emerging CDC guidelines. Pine Rest is a stand-alone psychiatric hospital with a maximum inpatient capacity of 198 patients on eight units. Five units consisting of 110 beds are dedicated to treating adults (generally ages 18-65), one unit with 26 beds is dedicated to treating older adults (generally older than 65 years of age), one unit with 36 beds treating children and adolescents (ages 6-17), and one unit with 26 beds that alternates between treating younger adults (ages 18-21) and adolescents (ages 14-17) depending on community needs. Prior to the COVID-19 pandemic, social gatherings for psychiatric inpatients included eating meals in the dining room, watching television or movies during leisure times, visiting with family and friends, standing at the nursing station waiting to talk to staff, receiving medication(s), or participating in therapeutic groups at Pine Rest. This report serves as a functional guideline that other psychiatric facilities may implement to decrease the transmission of person-to-person spread of infectious organisms in future epidemics.

\section{STATE EXeCUTIVE ORDERS (EO)}

On March 10, 2020, the governor of Michigan declared a State of Emergency due to the COVID-19 epidemic followed by EO designed to curb the spread of COVID-19 and expanded the scope of practice for specific medical providers (see Table 1). Another EO was issued to limit in-person visitation and required health care facilities to screen every individual entering a medical facility for COVID-19 symptoms. ${ }^{[4]}$ Subsequent EO prohibited in-person work not necessary to sustain or protect life. In April and May, EO increased access to telehealth services and authorized health care providers to use telehealth services as medically appropriate. ${ }^{[4]}$

\section{Pine Rest COVID-19 task force}

Starting March 11, 2020, Pine Rest COVID-19 task force met daily to determine necessary precautions. Also, Pine Rest began working with community medical facilities to assess potential surges in cases, avenues for testing inpatient psychiatric patients, and the need for a COVID-19 positive unit. Pine Rest initiated protocols to manage intrahospital spread of COVID-19 after admission nurses expressed concerns about adequate PPE supplies (March 11, 2020). At admission, patients were screened using evidence-based practices. ${ }^{[5]}$ If the patient screened positive, a registered nurse (specifically trained for PPE and COVID-19 symptoms) assessed the patient. Local acute care centers were used to facilitate COVID-19 testing when potential cases were identified. In mid-April, hospital precautions included single room occupancy, required masking for all $\mathrm{HCP}$, limiting the number of individuals in an enclosed room, encouraging physicians to utilize televideo services, and no visitors.

After admission, inpatients were not repeatedly tested for COVID-19 due to limited testing supplies, and supply chain and staffing challenges. Patients were retested if they manifested symptoms (fever, cough, shortness of breath, or other symptoms suggesting patient was acutely ill) while in care; they were tested to reduce the likelihood of outbreaks and to determine next steps for the patient's care (transfer to the SCU or to another acute care system). Also, symptomatic $\mathrm{HCP}$ triggered inpatient testing in high risk areas such as Older Adult Unit (OAU) as directed by the Kent County Health Department. To reduce risk of asymptomatic transmission, various mitigation strategies were used such as encouraging patients to mask, encouraging hand hygiene, and increased monitoring of vitals.

Similar to the inpatients, HCP were only tested for COVID19 if experiencing symptoms or current temperature exceeded $100 \mathrm{~F}$. HCP were screened prior to work for the following symptoms within the last two weeks; fever, cough, shortness of breath, loss of taste/smell, and/or two or more of the following: chills, sore throat, headache, muscle aches without recognized causes, or diarrhea/vomiting/nausea. If HCP reported symptoms, Infection Prevention was immediately contacted before reporting to work. Additional mitigation strategies included Pine Rest employees working remotely if not essential for inpatient care and telehealth for outpatient patient care.

Pine Rest absorbed the cost of the additional testing (both supplies and staff to perform swabs) and investment in PPE. Some of the additional cost was offset by funded grant applications but much of the financial burden was absorbed by Pine Rest operations. 
Table 1. Summary of pertinent executive orders in Michigan from March to August 2020

\begin{tabular}{|c|c|c|c|}
\hline Date & $\begin{array}{l}\text { Governor Whitmer's } \\
\text { Executive Order }\end{array}$ & Summary of Executive Order & Pine Rest Mandated Policies \\
\hline March 10 & 2020-04 & State of Emergency Declared in Michigan & $\begin{array}{l}\text { Cancelling events and hospital tours. } \\
\text { Training clinicians for telehealth services. } \\
\text { Training select HCP to handle an outbreak } \\
\text { situation. }\end{array}$ \\
\hline March 13 & 2020-06 & $\begin{array}{l}\text { Temporary restrictions on entry into health } \\
\text { care facilities: no visitors, must perform a } \\
\text { health evaluation of all who seek to enter the } \\
\text { facility }\end{array}$ & $\begin{array}{l}\text { Non-essential HCP to work from Home } \\
\text { announcement. HCP screening } \\
\text { checkpoints, ban of in-person visitation. }\end{array}$ \\
\hline March 17 & $2020-13$ & $\begin{array}{l}\text { Allows any licensed hospital to construct, } \\
\text { acquire, or operate a temporary mobile } \\
\text { facility for any health care purpose, } \\
\text { regardless of where the facility is located }\end{array}$ & $\begin{array}{l}\text { All therapists working out of office } \\
\text { (tele-therapy), restricting hospital census, } \\
\text { screening new admissions. }\end{array}$ \\
\hline March 23 & $2020-21$ & $\begin{array}{l}\text { Prohibit or restrict in-person work that is not } \\
\text { necessary to sustain or protect life, facilitate } \\
\text { ability of workers to work remotely }\end{array}$ & $\begin{array}{l}\text { Developed Special Care Unit, masking } \\
\text { HCP at screening checkpoints. }\end{array}$ \\
\hline March 29 & $2020-30$ & $\begin{array}{l}\text { Temporary relief from certain restrictions } \\
\text { and requirements governing the provision of } \\
\text { medical services necessary to support the } \\
\text { facility's response to COVID-19 }\end{array}$ & $\begin{array}{l}\text { All Hospital physicians being trained for } \\
\text { telehealth service, masking patients. }\end{array}$ \\
\hline April 8 & $2020-41$ & $\begin{array}{l}\text { To provide limited and temporary relief from } \\
\text { certain rules and requirements so as to enable } \\
\text { and encourage the use of electronic } \\
\text { signatures, remote notarizations, remote } \\
\text { witness attestations, and remote visitations }\end{array}$ & $\begin{array}{l}\text { Testing all patients for COVID-19 (4/24), } \\
\text { using QR codes at checkpoints to minimize } \\
\text { paper and pen, detox facilities set up to } \\
\text { begin swabbing }(5 / 4)\end{array}$ \\
\hline May 14 & $2020-86$ & $\begin{array}{l}\text { All health care providers are authorized and } \\
\text { encouraged to use telehealth services when } \\
\text { medically appropriate and upon obtaining } \\
\text { patient consent }\end{array}$ & Urgent care virtual service goes live (5/19). \\
\hline May 26 & 2020-104 & $\begin{array}{l}\text { Increased COVID- } 19 \text { testing by expanding } \\
\text { the scope of practice for certain professionals } \\
\text { for both ordering and testing }\end{array}$ & $\begin{array}{l}\text { Able to provide non-emergency } \\
\text { department COVID-19 testing in less than } \\
\text { three hours }(6 / 5) \text {. }\end{array}$ \\
\hline
\end{tabular}

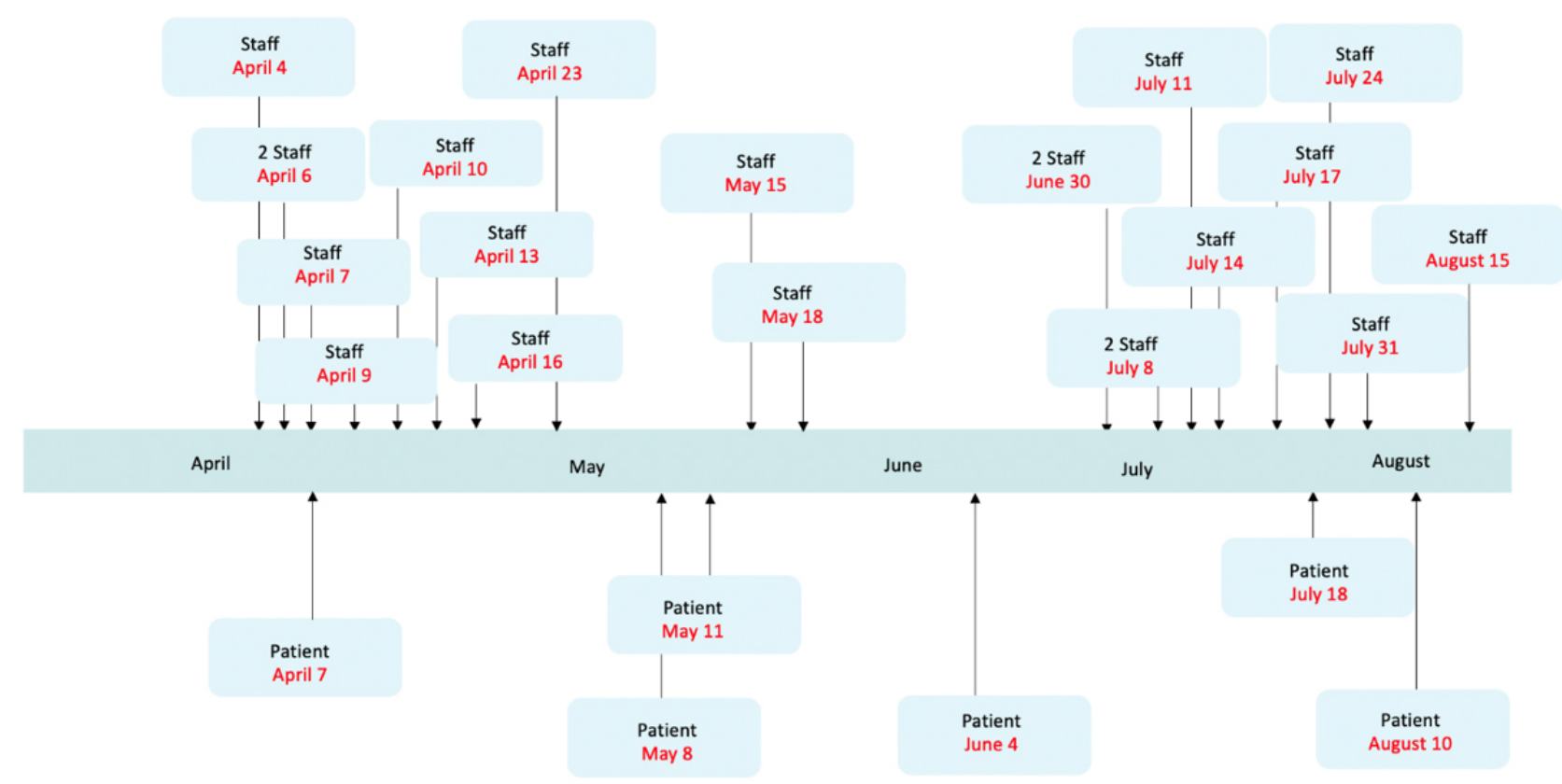

Figure 1. Timeline of COVID-19 positive tests at Pine Rest Christian Mental Health Services (non-special care unit patients and staff) from March to August 2020 


\section{COVID-19 INCIDENTS}

Intrahospital spread of COVID-19 became a concern after two incidents in the hospital (see Figure 1 and Table 2). One $\mathrm{HCP}$ who last worked on the Child and Adolescent Unit (CAU) on March 31, 2020 and tested positive for COVID19 on April 2, 2020. To contain a potential outbreak, all exposed children $(n=11)$ were transferred to a negativepressure unit for a 14-day quarantine period. For discharged children, parents were instructed to quarantine their child an additional 10 days at home. HCP and guardians of the exposed children were contacted by the health department. No additional patients or HCP from the incident tested positive for COVID-19.

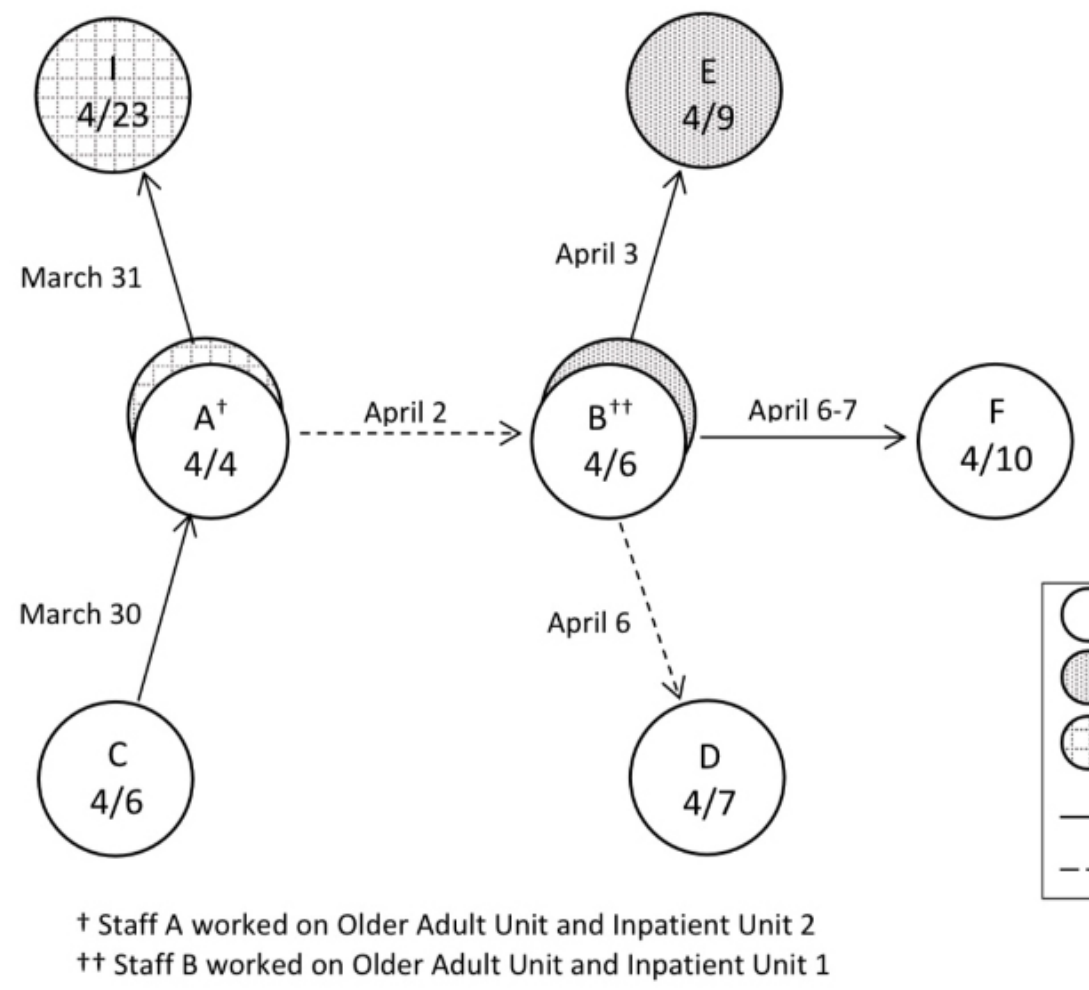

Older Adult Unit staff Inpatient Unit 1 staff Inpatient Unit 2 staff

$\longrightarrow$ Probable Exposure Possible Exposure

Figure 2. Dated employment tracing among de-identified Pine Rest Christian Mental Health staff with respective SARS-coV-2 positive test dates in Grand Rapids, Michigan

Table 2. Characteristics of Patients and Health Care Personnel (HCP) who tested positive for COVID-19 from March 1 to August 31, 2020

\begin{tabular}{|c|c|c|c|c|c|}
\hline Role characteristic & $\begin{array}{l}\text { Number positive } \\
\text { for COVID-19 }\end{array}$ & $\begin{array}{l}\text { Number Males } \\
\mathbf{N}[\%]\end{array}$ & $\begin{array}{l}\text { Age (years): Median } \\
\text { Minimum, Maximum }\end{array}$ & $\begin{array}{l}\text { Median length of } \\
\text { admission (days) }\end{array}$ & $\begin{array}{l}\text { Number admitted } \\
\text { to local hospital }\end{array}$ \\
\hline Total patients & $25^{\mathrm{a}}$ & $18[72 \%]$ & $\begin{array}{l}38.5 \\
19,92\end{array}$ & $\begin{array}{l}7\left[\mathrm{n}=251^{\text {st }} \text { admission }\right] \\
9\left[\mathrm{n}=3,2^{\text {nd }} \text { admission }\right]\end{array}$ & $2[8 \%]$ \\
\hline Patients treated on SCU & 22 & 17 [77\%] & $\begin{array}{l}38 \\
19,64\end{array}$ & $\begin{array}{l}7.5\left[\mathrm{n}=22,1^{\text {st }} \text { admission }\right] \\
9\left[\mathrm{n}=3,2^{\text {nd }} \text { admission }\right]\end{array}$ & 0 \\
\hline $\begin{array}{l}\text { Patients treated outside of } \\
\text { SCU }\end{array}$ & 3 & $1[33 \%]$ & $\begin{array}{l}53 \\
21,92\end{array}$ & $2[\mathrm{n}=3]$ & $2[66.7 \%]$ \\
\hline Total HCP & 21 & $4[19 \%]$ & $\begin{array}{l}32 \\
21,66\end{array}$ & $\mathrm{n} / \mathrm{a}$ & $6[28.6 \%]$ \\
\hline $\begin{array}{l}\mathrm{HCP} \text { providing direct } \\
\text { patient care on the } \mathrm{SCU}\end{array}$ & 0 & 0 & 0 & 0 & 0 \\
\hline $\begin{array}{l}\text { HCP providing direct } \\
\text { patient care outside of } \\
\text { SCU }\end{array}$ & 15 & $3[20 \%]$ & $\begin{array}{l}29.5 \\
21,66\end{array}$ & $\mathrm{n} / \mathrm{a}$ & $3[20 \%]$ \\
\hline
\end{tabular}

Note. $\mathrm{HCP}=$ Health Care Personnel, $\mathrm{SCU}=$ Special Care Unit, $\mathrm{n} / \mathrm{a}=$ not applicable; ${ }^{\mathrm{a}} 3$ of 25 patients were readmitted to Pine Rest approximately one month after initial discharge for 28 total admissions. 
Another HCP who last worked on the OAU on April 2, 2020 tested positive for COVID-19 on April 5, 2020 (see Figure 2). OAU admissions were suspended for 48 hours starting on April 5, 2020. Within five days, four HCP who worked on OAU and one OAU patient tested positive for COVID-19. On April 6, 2020, all patients were moved from the open to the closed area of OAU (10 beds) with negative-pressure capabilities. One patient was transferred to a general medical facility after developing symptoms and testing positive for COVID19 (April 7, 2020). No additional OAU patients or HCP tested positive for COVID-19.

On April 3, 2020, Pine Rest started onsite COVID-19 testing. SCU was opened on May 4, 2020 for adult patients only. Leadership staffed SCU with volunteer nurses, psychiatric technicians, psychiatrists and internists. These HCP received enhanced training in PPE donning and doffing. The following SCU inclusion criteria were established: age < 65 years, non-severe infection based on National Institute of Health criteria, ${ }^{[6]}$ and at least one psychiatric diagnosis currently requiring inpatient hospitalization. These criteria were established because Pine Rest as a psychiatric facility does not have advanced life support capabilities. Evidence of respiratory failure, septic shock, or multi-organ dysfunction required transfer to an acute care setting. ${ }^{[6]}$

At Pine Rest, 25 [1.0\%] of 2,394 total patients tested positive for COVID-19 between March 1 and August 31, 2020. The 25 admitted patients included 22 SCU patients transferred to Pine Rest due to their known COVID-19 status and need for behavioral health care. Among the 25 COVID-19 positive patients, three patients were readmitted approximately one month after their first Pine Rest discharge, totaling 28 COVID-19 positive admissions to Pine Rest between March 1 and August 31, 2020. Explanation regarding the three patients who were COVID-19 positive and admitted twice is as follows: one patient was first admitted in May to an adult inpatient unit and transferred to SCU upon positive test, the second admission was directly to SCU in June 2020; one patient was directly admitted to SCU in both May and June 2020; and one patient was directly admitted to SCU in both June and July 2020.

Not all 25 patients received care on the SCU. There were three patients who were never admitted to the SCU: two patients (one from OAU in early April and one from an adult inpatient unit in early August) were transferred to a local hospital after testing positive for COVID-19 and a third patient was discharged home, in early May, following a positive test.

The remaining 22 patients ( 25 total admissions due to the three patients who were readmitted) were either transferred from a Pine Rest adult unit to the SCU (admissions $=3$ ) or were directly admitted to SCU (admissions = 22). Three patients seeking behavioral health care were admitted to various Pine Rest adult units and then transferred to SCU upon testing positive for COVID-19. There were 22 patients who were transferred directly to SCU from other Michigan facilities due to being COVID-19 positive between the dates of May 6 and July 15, 2020. While in operation, maximum SCU occupancy at any one time was six out of a possible eight beds.

Average age of COVID-19 positive patients [ $\mathrm{n}=25]$ was $38.5 \pm 16.6$ years, and the majority were male (see Table 2 ). Average length of first $[n=22]$ and second $[n=3]$ psychiatric hospitalization were $9 \pm 4$ days.

No patients died from COVID-19 while receiving care at Pine Rest. However, one 68-year-old female patient was exposed to a Pine Rest HCP who later tested positive for COVID-19 on April 6, 2020. Patient was admitted to the OAU on March 13, 2020, discharged April 1, 2020, and not tested for COVID-19 during her Pine Rest admission and hospitalization. On April 4, 2020, her family took her to the local Emergency Department (ED) for a cough. She tested negative for Influenza A\&B and was sent home. She returned to the ED on April 7, 2020 for worsening shortness of breath and tested positive for COVID-19. The patient was admitted to the hospital for pneumonia, acute respiratory failure, and COPD exacerbation and died on May 2, 2020 in the ICU.

At Pine Rest, 21 [1.1\%] of 1,878 total HCP tested positive for COVID-19 between March 1 and August 31, 2020. Among the 21 COVID-19 positive HCP, 15 [71.4\%] provided direct clinical care on various units, zero provided care on the SCU, and six had roles that required no direct patient care. Average age among COVID-19 positive HCP providing direct patient care [ $n=15$ ] was $29.5 \pm 13.5$ years, majority were female [81\%], and 3 [20\%] were admitted to local medical hospital for treatment. No HCP died from COVID-19 acquired while working at Pine Rest.

\section{Discussion}

CDC mitigation protocols adapted for psychiatric in-patient care limited transmission of COVID-19 within Pine Rest. Over a five month period, only six of 2369 non-SCU patients $(0.25 \%)$ were identified as COVID-19 positive after admission to Pine Rest. An additional 22 patients were transferred to Pine Rest for behavioral health care due to their COVID-19 status. Fifteen HCP with direct patient contact tested positive for COVID-19. There was only one documented instance of likely HCP to patient transmission and no documented instances of patient-to-patient transmission. Using full PPE donning and doffing protocol, there was no 
patient to HCP transmissions. These findings were consistent with transmission at a Wyoming inpatient psychiatric facility following two patients testing positive for COVID-19. ${ }^{\text {[] }}$

Previous respiratory viral precautions proved to be inadequate in slowing the spread of COVID-19 in hospitals and other medical facilities for the following reasons: mild symptoms not considered severe enough to be COVID-19, unusual symptoms not readily associated with COVID-19, or asymptomatic. $^{[8,9]}$ As fear regarding COVID-19 spread inside and outside hospitals, the strain on the healthcare system as a whole increased. ${ }^{[10]}$ In addition to the strain of time and resources, the emotional and intellectual strain placed on healthcare providers became especially prominent when these professionals were asked to provide unfamiliar care such as treating patients with acute medical illness cooccurring with acute mental illness. As inpatient hospitals across the state of Michigan and across the USA reduced and sometimes even paused admissions, patients with the most severe acute mental illness were often times treated in the emergency department or on non-psychiatric medical floors. This practice was especially true for patients who had an acute psychiatric illness and tested positive for COVID-19.

Pine Rest's ability to quickly and safely establish safety protocols consistent with CDC guidelines can serve as a blueprint for the future. This report provides an example of evidence-based safety precautions implemented that permitted an inpatient psychiatric hospital to function close to pre-pandemic capacity and behavior. In addition, the creation and management of the SCU resulted in the treatment of patients with acute mental and viral illness without compromising the health of staff or other patients. Given the majority of SCU patients were transferred from other medical facilities throughout Michigan, the SCU also addressed and alleviated unique psychiatric and medical management needs during the pandemic. Presumably, the SCU allowed medical and mental health providers to provide high quality care within their area of expertise.

During the COVID-19 pandemic, algorithms and models were effectively used to determine how to allocate physical resources in hospitals. ${ }^{[11,12]}$ Extension of these algorithms and models to psychiatry would be beneficial. Specifically, reallocation of psychiatric providers during a pandemic may accommodate significant shifts in patients seeking outpatient rather than inpatient care. In addition, the models may provide estimates of the effect of social isolation, social distancing, negative stimulus such as social media and news reports, and fear of physical illness on the mental health of individuals and communities.

\section{Limitations}

COVID-19 under-reporting is a potential limitation. Admitted patients were only retested if they developed COVID-19 symptoms. Feasibly, asymptomatic patients could have been infected with COVID-19 and tested negative upon admission. These asymptomatic inpatients could have infected other inpatients and HCP prior to being discharged. Following discharge, patients were not tracked or re-tested for COVID19. Although speculative, this under-reporting was probably minimal given the limited number of cases identified outside the SCU unit. Despite limitations, implementation of hospital-wide protocols in compliance with CDC recommendations can drastically reduce COVID-19 spread. This type of rapid response to a novel virus can be applied in the future by inpatient psychiatric hospitals.

\section{Conclusions}

As a novel virus, COVID-19 created significant challenges providing safe mental health services in full-spectrum psychiatric hospitals. Typically, psychiatric treatments involve social gatherings and group therapies in a congregate living environment. These interactions have the potential of spreading COVID-19 rapidly. Multiple strategies (COVID19 testing and masking of patients and HCP, restricting visitors, and creation of SCU) were effectively implemented. SCU provided care for behavioral health patients that tested positive for COVID-19 prior to and after admission. SCU became the last resort for many patients suffering from a mental health crisis and COVID-19, as most medical and psychiatric hospitals in Michigan were not equipped to safely admit or provide treatment.

The COVID-19 pandemic resulted in a psychiatric hospital's innovative application of CDC and state guidelines to safely manage patients at high risk for COVID-19. Utilizing risk mitigation strategies in the development of SCU minimized the spread of COVID-19 while providing effective behavioral health care. From a public health perspective, the SCU addresses infection prevention and control as well as behavioral health needs, both at elevated risk during a pandemic. Medical practice should continue to strive to address evidence-based and cost-effective models that effectively address the health of the patient and the public health of community simultaneously. In the future, SCU development may want to consider admitting all adults without age limitations and establishing separate SCU for adolescents and youth. Economic factors should be evaluated prior to opening future SCU's. Pine Rest has demonstrated that quality behavioral health care can be safely provided at inpatient psychiatric facilities while preventing the transmission of a virus during a pandemic. 


\section{ACKNOWLEDGeMENTS}

The authors would like to thank Pine Rest Christian Mental Health Services for providing the information to make this report possible, and members of the COVID-19 committee for their patience and willingness to help. Members of the COVID-19 task force included infection prevention, Chief Medical Officer, director of nursing, quality improvement, risk management, ECT, Hospital and Residential Services (HRS) medical staff, HRS Leadership Team, Outpatient Services Leadership, Pharmacy, Clinical Service Managers, Support Staff, Facilities/Housekeeping, Data Collection/Analysis, Behavioral Health Solutions, Human Re- sources, Chief Operating Officer, Chief Financial Officer, and Chief Informatics Officer. Finally, the authors would like to thank all Pine Rest healthcare providers especially those who worked on the Special Care Unit for providing excellent care to all patients throughout the COVID-19 pandemic.

\section{Contribution}

Richelle Payea, Joshua Foster and David Meisinger contributed equally to the first draft of the manuscript.

\section{CONFlicts of InTERest Disclosure}

The authors declare they have no conflicts of interest.

\section{REFERENCES}

[1] Substance Abuse and Mental Health Services Administration. Michigan 2017 Mental Health National Outcome Measures (NOMS): SAMHSA Uniform Reporting System. Rockville, MD: US Department of Health and Human Services, Substance Abuse and Mental Health Services Administration; 2017 [Accessed February 3, 2021]. Available from: https://www.samhsa.gov/data/sites/defa ult/files/cbhsq-reports/Michigan-2017.pdf

[2] Michigan Department of Human Services. Total \& Senior (Ages 65 \& Over) Population, Michigan 2000-2019. Lansing, MI: Michigan Department of Human Services; 2019 [Accessed February 3, 2021]. Available from: https://www.mdch.state.mi.us/osr/Popul ation/npPopBYSeniors.asp

[3] State of Michigan. Coronavirus Michigan Data. Lansing, MI: Michigan.Gov; 2020 [Accessed February 3, 2021]. Available from: https://www.michigan.gov/coronavirus/0, 975 3,7-406-98163_98173---,00.html

[4] Michigan Legislature. Executive Orders. Lansing, MI: Michigan Legislature; 2020 [Accessed February 3, 2021]. Available from: http://www.legislature.mi.gov/(S (u2oasffofb23 $\mathrm{x} 11 \mathrm{qzftbelhr}$ ))/mileg. aspx?page=executiveorders

[5] Nicola M, O'Neill N, Sohrabi C, et al. Evidence based management guideline for the COVID-19 Pandemic- Review article. International Journal of Surgery. 2020; 77: 206-216. PMid: 32289472. https://doi.org/10.1016/j.ijsu.2020.04.001

[6] National Institute of Health. Overview of COVID-19: Epidemiology, Clinical Presentation, and Transmission. Rockville, MD: National Institute of Health; 2020 [Accessed February 3, 2021]. Available from: https://www. covid19treatmentguidelines.nih.gov /overview/

[7] Callaghan A, Chard AN, Arnold P, et al. Screening for SARS-CoV2 Infection Within a Psychiatric Hospital and Considerations for Limiting Transmission Within Residential Psychiatric Facilities Wyoming, 2020. MMWR Morb Mortal Wkly Report. 2020; 69: 825829. PMid: 32614815 . https ://doi .org/10.15585/mmwr.mm69 $26 \mathrm{a} 4$

[8] Klompas M. Coronavirus Disease 2019 (COVID-19): Protecting Hospitals From the Invisible. Annals of Internal Medicine. 2020; 172(9): 619-620. PMid: 32160299. https ://doi.org/10.7326/ M20-0751

[9] Yu XH, Yang RR. COVID-19 Transmission through Asymptomatic Carriers Is a Challenge to Containment. Influenza and Other Respiratory Viruses. 2020; 14(4): 474-475. PMid: 32246886. https : //doi.org/10.1111/irv. 12743

[10] Barrett CK, Khan YA, Mac S, et al. Estimation of COVID-19Induced Depletion of Hospital Resources in Ontario, Canada. Canadian Medical Association Journal. 2020; 192(24): E640-E646. PMid: 32409519. https://doi.org/10.1503/cmaj . 200715

[11] Weissman GE, Crane-Droesch,A, Chivers C, et al. Locally Informed Simulation to Predict Hospital Capacity Needs During the COVID-19 Pandemic. Annals of Internal Medicine. 2020; 173(1): 21-28. PMid: 32259197. https://doi.org/10.7326/M20-1260

[12] Erik C. An Agent-Based Model to Evaluate the COVID-19 Transmission Risks in Facilities. Computers in Biology and Medicine. 2020; 121: 103827. PMid: 32568667. https://doi.org/10.1016/j. compbiomed.2020.103827 